\title{
Using Low Energy-Consuming Microwave Technology to Regenerate High Carbon-Containing Pt Catalyst
}

\author{
Chien-Li Lee ${ }^{1} \&$ Chih-Ju G. Jou ${ }^{2}$ \\ ${ }^{1}$ Research and Development Center for Water Resource and Conservation, National Kaohsiung First University \\ of Science and Technology, Taiwan \\ ${ }^{2}$ Department of Safety, Health and Environmental Engineering, National Kaohsiung First University of Science \\ and Technology, Taiwan \\ Correspondence: Chih-Ju G. Jou, 2, Juoyue Road, Nantsu District, Kaohsiung 811, Taiwan. Tel: 886-7-601-1000 \\ ext.2316. E-mail: george@ccms.nkfust.edu.tw
}

Received: March 5, 2014 Accepted: September 10, 2014 Online Published: September 24, 2014

doi:10.5539/ep.v3n4p41 URL: http://dx.doi.org/10.5539/ep.v3n4p41

\begin{abstract}
In this research, the high carbon-containing (coke, $>20 \mathrm{wt} \%$ ) Pt catalyst wasted from a full-scale petrochemical plant are regenerated in quartz and borax glass reactors by applying $250 \mathrm{~W}$ microwave irradiation for 18 hours. When irradiated with microwave substances of various dielectric characteristics will consume the microwave energy; the quantity of energy consumed is proportional to dielectric constant. Because borax glass has higher dielectric constant than quartz glass (e.g. 4.6 vs. 3.6 F/M), it causes higher energy loss than quartz glass. Laboratory results reveal that the removal of coke is smaller for the sample placed in the borax glass reactor than in the quartz glass container (17.7 vs. $25.9 \%$ ). On the other hand, higher MW output power leads to stronger electrical field to influence the mutual reactions between microwave and dielectric materials (e.g. the absorption of microwave energy), and the overall energy efficiency. The laboratory results also show that when the microwave energy is increased from 250 to $450 \mathrm{~W}$, the carbon removal rate is raised from 25.9 to $38.1 \%$ with the sample placed in quartz glass reactor. Using the microwave energy to regenerate high carbon-containing (coke) Pt-catalyst as studied in this research is an innovated technology.
\end{abstract}

Keywords: microwave energy, Pt-catalyst, catalyst regeneration

\section{Introduction}

Prosperous global economic development (D'Ippolitoa et al., 2010; Hu \& Kao, 2007) leads to continually increasing demand of energy that gradually depletes reserves of petrochemical energy (Veziroğlu \& Şahin, 2008; Tonna \& Peretz, 2007; Bahadori \& Vuthaluru, 2010; Ismail \& Mehta, 2011). One solution to alleviate this problem is to renew and improve the petrochemical and petroleum processes for improving the product quality and increasing the product add-on value that will stimulates the rapid development of petrochemical industries. These measures include: recombining heavy naphtha to raise the gasoline octane value (Marafi \& Stanislaus, 2008), and cracking naphtha into olefins to adjust the supply of gasoline and increase the fuel value (Mazzieri et al., 2008).

The catalyst used in petrochemical and petroleum industry are converted to coke or carbon products during the process of hydrocarbon cracking or condensation; the carbon blocks the catalyst particle surface pores thus causing the catalyst to lose its activity that adversely affects the quantity and quality of products and by-products as well as the objective of waste reduction (Rajaei et al., 2012). For example the loss of activity for Pt-based catalysts is caused by either deposit of carbon or sintering of metal particles, and the formation of coke is regarded as the major reason for loss of catalyst activity (Nagaokaet al., 2001). Additionally, when the catalyst oxidation temperature is raised to $400 \sim 550{ }^{\circ} \mathrm{C}$ in the absence of chlorine gas, Pt sintering may also contribute to the loss of catalyst activity (Arteaga et al., 1999). For industrial application, the coke deposit is usually removed with oxidation in a fluidized catalyst unit operation to regenerate the catalyst for maintaining the catalyst high reactivity (Dimitriadis et al., 1998). However, during this regenerating process, hot spots may be formed in the catalyst bed, and some catalyst sintering may occur. Hence, various oxidizing agents such as oxygen, air, $\mathrm{CO}_{2}$, $\mathrm{H}_{2}$ and $\mathrm{N}_{2}$ have been used in order to reduce as much as possible the catalyst sintering problem (Lee et al., 2012). Pieck et al. pointed out that the complete oxidation of metallic coke occurs between 280 and $400{ }^{\circ} \mathrm{C}$, whereas 
complete oxidation of the coke associated with $\mathrm{Al}_{2} \mathrm{O}_{3}$, or the acidic position occurs between 280 to $400{ }^{\circ} \mathrm{C}$ (Dimitriadis et al., 1998; D'Ippolitoa et al., 2010). Johnsson and Maryland indicated that treatment of the coke catalyst in inert gas is important prior to measuring the burning rate because the burning results are valid only after all volatile substances have been removed (Dimitriadis et al., 1998).

The microwave energy is converted into heat energy directly through mutual reactions between the molecules to be heated and the electromagnetic field. When a substance is subject to microwave irradiation, the rapid molecular movement causes the temperature to rise, and the temperature increasing rate is proportional to the dissipation factor (tangent $\delta$ ) that is defined as the ratio between dielectric loss factor $\left(\varepsilon^{\prime \prime}\right)$ and dielectric constant $\left(\varepsilon^{\prime}\right)$ (Appleton et al., 2005; Ku et al., 2001; Venkatesh \& Raghavan, 2004):

$$
\tan \delta=\varepsilon^{\prime \prime} / \varepsilon^{\prime}
$$

The dielectric constant is a measurement of the capacity of the substance being irradiated to resist the microwave radiation whereas the dielectric loss factor measures the capacity of the substance to dissipate the energy. In other words, when microwave penetrates a sample, the energy absorbing rate is dependent of the dissipation factor $(\delta)$; substances with higher dissipation factor absorbs more microwave energy with higher temperature increase so that they are easier to be decomposed. The microwave radiation may penetrate substances and accumulates energy in the substance being irradiated ( $\mathrm{Ku}$ et al., 2001), and the energy transmission is dependent of surface dissipation more than geometric related parameters; thick samples can be rapidly and evenly heated with microwave energy as thinner samples (Venkatesh \& Raghavan, 2004). Hence, this unique feature for microwave radiation to generate and transfer heat has been used extensively as an effective method for decomposing chlorine-containing organic substances. For example, methods using microwave-induced nano-scale zero-valence iron to decompose chlorobenzene (Jou et al., 2011, 2010; Lee \& Jou 2011), tetrachloroethylene, and pentachlorophenol (Lee et al ., 2012), and microwave-included nano-scale zero-valence copper to decompose benzene are quite efficient with many advantages. Additionally, the microwave-induced waste cordierite combined with nano-scale zero-valence iron, titanium oxide, and copper/iron bi-metal are also effective in decomposing chloro-containing organic substances (Lee \& Jou, 2013, 2012; Lee et al., 2010).

With increasing applications of catalysts, the need for regenerating the wasted catalyst becomes more important. Industries have used batch or continuous-flow methods to carry out the regenerating process for extending the useful life of catalysts in order to reduce the production costs. The occurrence of hot spot and sintering of some catalyst in the catalyst bed makes it necessary to replace some catalyst in the bed especially for catalysts containing more than $20 \%$ coke. The replaced coke needs to be regenerated and reused to alleviate environmental impacts. The wasted Pt catalyst with high coke content has high dielectric constant so that it is a perfect media to absorb microwave radiation and convert it into heat energy. Such characteristics can be used to regenerate the wasted high coke-containing Pt catalyst using microwave irradiation for more efficient with less adverse environmental impacts. In this research, regenerating the wasted Pt catalyst that contains high percentage of coke using microwave irradiation is studied to test the feasibility of this regeneration method. The success of this study will be developed into a novel concept that is different from the conventional method in both theory and practice for regenerating wasted Pt catalyst.

\section{Experimental Equipment and Method}

\subsection{Experimental Equipment}

The microwave oven used in the laboratory study is equipped with PID to control the output power; its frequency is $2.45 \mathrm{GHz}$ with the maximum output of $750 \mathrm{~W}$. All reactors are custom-made $80-\mathrm{mL}$ borax and quartz ground glass containers with wide mouth connected to a tail gas collecting pipe made of the same material. The wasted Pt catalyst that contains 32-35 wt $\%$ coke, $2-3 \mathrm{wt} \% \mathrm{Pt}$ are in particle form with diameters between 1.4-1.6 mm.

\subsection{Experimental Method}

The Pt regenerating experiment was conducted batch-wise operations with each batch using 30 grams of coke that contains $30-35 \% \mathrm{Pt}$ catalyst. Each batch consisting of 5 reactors each containing 6 grams of the coke/Pt catalyst samples were prepared in laboratory, and then subject to either $250 \mathrm{~W}$ or $450 \mathrm{~W}$ microwave irradiation. The exposure time for each batch is was set at 5 durations of $0,4,8,13$ and 18 hours. The microwave treated samples were analyzed using an impedance analyzer (Agilent Co, 4291B) with $2.45 \mathrm{GHz}$ at $25{ }^{\circ} \mathrm{C}$. Samples of the wasted Pt-containing coke were found to have $11.7 \mathrm{~F} / \mathrm{m}$ dielectric constant, and $13.7 \mathrm{~F} / \mathrm{m}$ dielectric loss coefficient. 


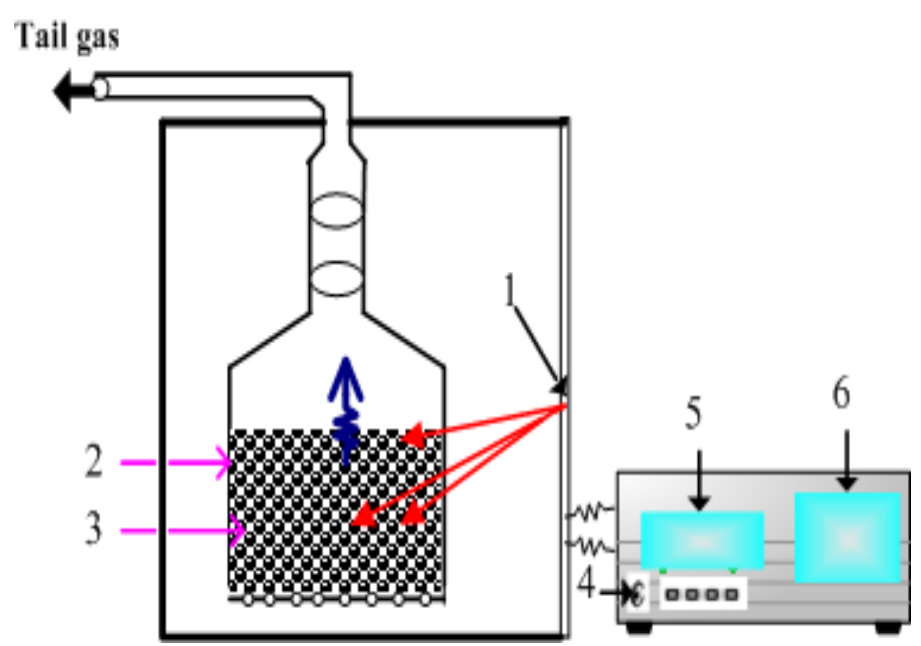

Figure 1. Schematic diagram of the experimental setup (1. Microwave emitter; 2. Reactor; 3. Wasted Pt-containing coke; Electric current regulator; 5. Galvanometer; 6. Microwave energy indicator)

\section{Results and Discussion}

\subsection{Influence of Reactor Material on the Removal of Coke from the Wasted Pt Catalyst}

Irradiation of a substance by microwave will cause loss of energy, and the loss is proportional to the dielectric constant of the substance. In this research, the Pt catalyst that contains high percentage of coke is put in a reactor, and the reactor is placed in the microwave oven to be irradiated for carrying out the regeneration experiment. If the reactor has a high dielectric constant that leads to high energy loss, the microwave energy that passes through the reactor wall to reach the Pt catalyst will be proportionally reduced. The loss of microwave energy when the microwave radiation passes through the container will reduce the quantity of microwave energy to reach the sample being regenerated and the amount of the microwave energy to penetrate the sample media. The microwave penetration is defined as when the microwave energy that reaches the sample has been reduced to $36.8 \%$ of its original level;

$$
d p=\frac{\lambda_{o} \sqrt{\varepsilon^{\prime}}}{2 \pi \varepsilon^{\prime \prime}}
$$

Where: $\quad d p=$ penetration depth $(\mathrm{cm})$;

$$
\lambda_{o}=\text { Microwave free space wavelength }(12.2 \mathrm{~cm})
$$

On the other hand, when microwave passes through the coke contained in Pt-catalyst, the Pt-catalyst/coke internal energy instantaneously rises, and the stored energy is subsequently released to cause molecular polarization and electronic vibration, these movements lead to high temperature due to friction. When subject to 250-W microwave irradiation for 4, 8, 13 and 18 hours in quartz-glass reactor and borax-glass reactor, the Pt-catalyst coke shows higher coke removal efficiency in quartz-glass reactor than in borax glass reactor (25.9 vs. 17.7\%) (Figure 2). The dielectric coefficient and dielectric loss coefficient for borax glass are 4.6 and $0.017 \mathrm{~F} / \mathrm{M}$, respectively; they are higher than those (3.6 and $0.0018 \mathrm{~F} / \mathrm{M}$, respectively) for quartz glass so that more loss of microwave energy is observed for borax-glass reactor than quartz-glass reactor. This observation is also confirmed by the results calculated using Equation (2). 


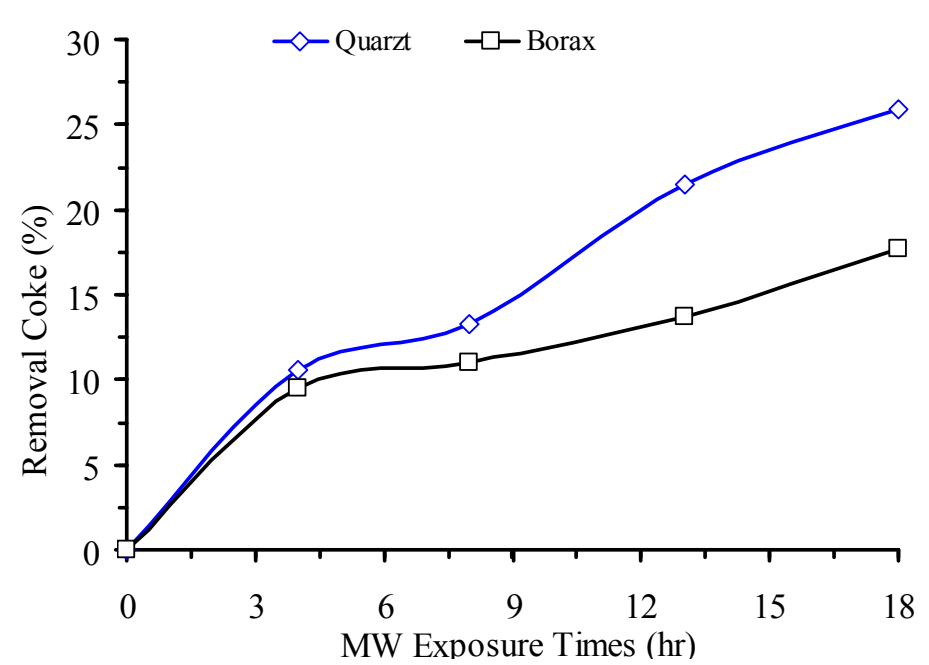

Figure 2. Efficiency of coke removal (\%) vs. microwave exposure time (hr)

\subsection{Influence of Microwave Sources on Coke Removal from Wasted Pt Catalyst}

Microwave energy is directly transmitted though the mutual reaction between molecule and electromagnetic filed to convert the electromagnetic energy into heat energy. The high electrical field frequency causes the metal contained in the catalyst to absorb more microwave energy thus leading to stronger electro-potential attraction. This causes the electrons to move rapidly to produce more friction heat. On the other hand, the microwave output power will affect the electrical field intensity inside the material; a larger output power leads to stronger electrical field so that the mutual reaction between microwave and media (absorption of microwave energy), and the overall energy efficiency are affected. When Pt-catalyst containing coke is placed in quartz glass reactor to be irradiated with $250 \mathrm{~W}$ and $450 \mathrm{~W}$ microwave for $0,4,8,13$, and 18 hours. Results shown in Figure 3 reveal that the carbon removal efficiencies increase from $25.9 \%$ for $250 \mathrm{~W}$ to $38.1 \%$ for $450 \mathrm{~W}$.

The high coke-containing Pt-catalyst has been removed from the catalyst removed from petrochemical industrial processes, it still contains volatile organic matter; the VOC is found with laboratory measurement to release 70 ppm at $23{ }^{\circ} \mathrm{C}$ and $170 \mathrm{ppm}$ at $55^{\circ} \mathrm{C}$. Because the laboratory studies conducted in this research were carried out under anaerobic conditions, during the initial stage of microwave irradiation, all VOC's contained in the Pt-catalyst undergo pyrolysis to attach on the catalyst particle surface that adversely impact the efficiency of carbon removal. The calculation using Eq. (2) shows that the penetration depth for microwave is $4.9 \mathrm{~mm}$. Using X-ray photoelectron spectroscopy (XPS) to analyze the Pt-catalyst, the resulting the X-ray photoelectron spectra (Figure 4) demonstrate that the surface substance is $\mathrm{PtCl}_{4}$.

When the Pt-catalyst containing more than $20 \mathrm{wt} \%$ coke is used in the process, the vigorous activation of coke produces high temperature thus leading to the sintering of catalyst to form lumps with coke that may affect the transportation of the catalyst and even cause accidents. Hence, such regenerated Pt-catalyst coke needs to be replaced with new Pt-catalyst; this catalyst replacement is costly. However, the replaced Pt-catalyst coke can be regenerated using microwave energy to re-activate Pt-catalyst. Hence, the wasted Pt-catalyst can be recycled and reused. The use of microwave regeneration method is a new technology allowing the petrochemical industry to achieve economic sustainable development for the petrochemical industry. 


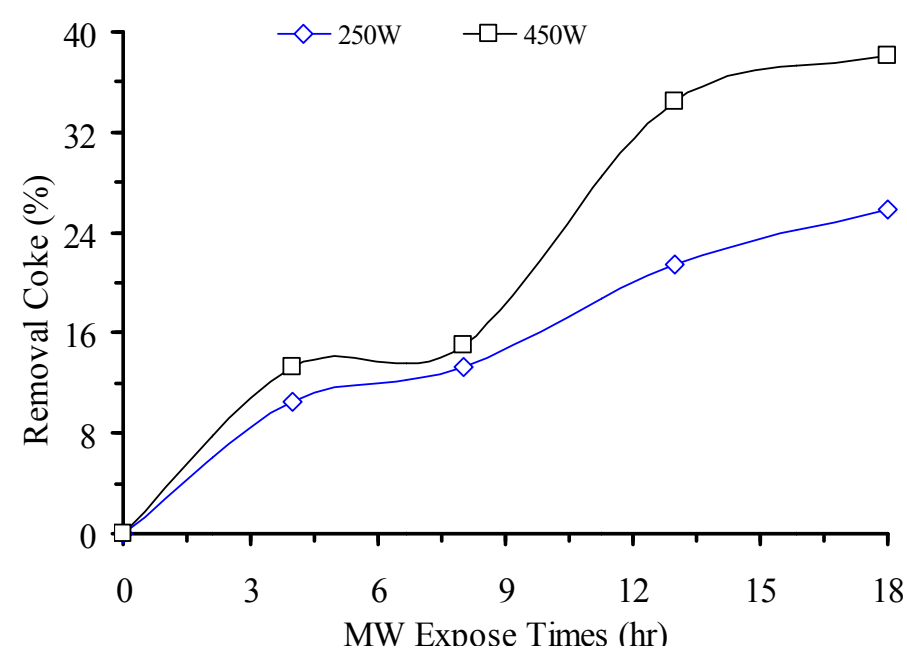

Figure 3. Removal of coke from the regenerated Pt-catalyst/coke at various irradiation times for 250 and $450 \mathrm{~W}$ microwave energy

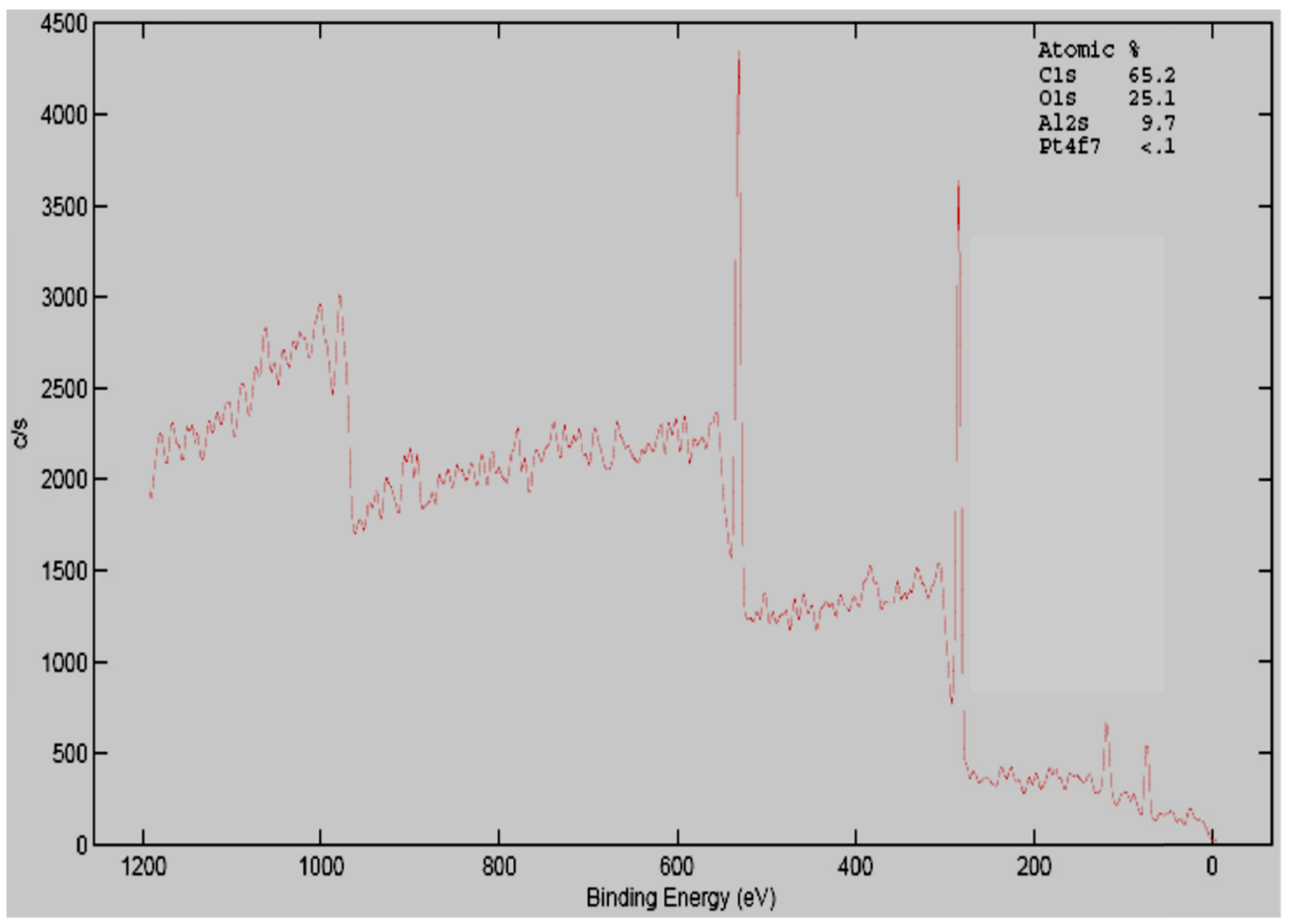

Figure 4. X-ray photoelectron spectra for Pt-catalyst containing high percentage of coke

\section{Conclusion}

The contact of microwave with a substance will cause the microwave energy to be absorbed the substance, and the energy absorbed is proportional to the dielectric constant of the substance. Borax glass has higher dielectric constant than quartz glass ( $4.6 \mathrm{vs} 3.6 \mathrm{~F} / \mathrm{M})$; hence, when microwave radiation passes through borax glass, more energy is absorbed than by quartz glass. Results of laboratory studies show that irradiating the Pt-catalyst/coke placed respectively in borax and quartz glass containers with microwave radiation under similar conditions (250 W for 18 hours), the sample in borax glass container shows lower coke removal efficiency than that in quartz glass container (17.7 vs. $25.9 \%)$. On the other hand, stronger microwave energy influences the interaction between microwave radiation and the media (the absorption of microwave energy), and the overall energy utilization. When the microwave output power increases from 250 to $450 \mathrm{~W}$, the carbon removal efficiency is raised from 25.9 to $38.1 \%$ in quartz glass reactor. Studies conducted in this research demonstrate the feasibility of using microwave energy to regenerate and reactivate Pt-catalyst that contains high portion of coke. This new technology allows the recovery and reuse of wasted Pt-catalyst that assists in alleviating adverse environmental 
impacts and promoting sustainable industrial development.

\section{References}

Appleton, T. J., Colder, R. I., Kingman, S. W., Lowndes, I. S., \& Read, A. G. (2005). Microwave technology for energy-efficient processing of waste. Applied Energy, 81, 85-113. http://dx.doi.org/10.1016/j.apenergy.2004.07.002

Arteaga, G. J., Anderson, J. A., \& Rochester, C. H. (1999). Effects of catalyst regeneration with and without chlorine on heptane reforming reactions over $\mathrm{Pt} / \mathrm{Al}_{2} \mathrm{O}_{3}$ and $\mathrm{Pt}-\mathrm{Sn} / \mathrm{Al}_{2} \mathrm{O}_{3}$. Journal of Catalysis, 187, 219-229. http://dx.doi.org/10.1006/jcat.1999.2610

Bahadori, A., \& Vuthaluru, H. B. (2010). Estimation of energy conservation benefits in excess air controlled gas-fired systems. Fuel Processing Technology, 91, 1198-1203. http://dx.doi.org/10.1016/j.fuproc.2010.03.033

D’Ippolitoa, S. A., Especel, C., Epron, F., Marécot, P., \& Pieck, C. L. (2010). $\mathrm{O}_{2}$ and $\mathrm{O}_{3}$ regeneration of $\mathrm{PtReSn} / \mathrm{Al}_{2} \mathrm{O}_{3}$ and $\mathrm{PtReGe} / \mathrm{Al}_{2} \mathrm{O}_{3}$ naphtha reforming catalysts prepared by catalytic reduction. Applied Catalysis A: General, 388, 272-277. http://dx.doi.org/10.1016/j.apcata.2010.09.001

Dimitriadis, V. D., Lappas, A. A., \& Vasalos, L. A. (1998). Kinetics of combustion of carbon in carbonaceous deposits on zeolite catalysts for fluid catalytic cracking units (FCCU) comparison between Pt and non Pt-containing catalysts. Fuel, 77, 1377-1383. http://dx.doi.org/10.1016/S0016-2361(98)00033-7

Hu, J. L., \& Kao, C. H. (2007). Efficient energy-saving targets for APEC economies. Energy Policy, 35, 373-382.

Ismail, S., \& Mehta, P.S. (2011). Evaluation of the effects of fuel and combustion-related processes on exergetic efficiency. Fuel, 90, 1818-1825. http://dx.doi.org/10.1016/j.fuel.2010.11.017

Jou, C. J. G., Lee, C. L., Lin, C., \& Huang, H. W. (2010). Combining zero-valent iron nanoparticles with microwave energy to treat chlorobenzene. Journal of the Taiwan Institute of Chemical Engineers, 41, 216-220. http://dx.doi.org/10.1016/j.jtice.2009.08.012

Jou, C. J. G., Lee, C. L., Wu, C. R., Hsieh, S. C., \& Andy Hong, P. K. (2011). Enhance degradation of chlorobenzene by microwave-induced zerovalent iron: Particle effects and activation energy. Environmental Chemistry Letters, 9, 355-359. http://dx.doi.org/10.1007/s10311-010-0286-y

Ku, H. S., Siu, F., Siores, E., Ball, J. A. R., \& Blicblau, A. S. (2001). Applications of fixed and variable frequency microwave (VFM) facilities in polymeric materials prcessing and joining. Journal of Materials Processing Technology, 113, 184-188. http://dx.doi.org/10.1016/S0924-0136(01)00642-2

Lee, C. L., \& Jou, C. J. G. (2011). Reduced degradation of chlorobenzene in co-solvent solution using nano-scale zero-valent iron with microwave irradiation. Environmental Engineering Science, 28, 191-195. http://dx.doi.org/10.1089/ees.2010.0152

Lee, C. L., \& Jou, C. J. G. (2012). Integrating suspended copper/iron bimetal nanoparticles and microwave irradiation for treating chlorobenzene in aqueous solution. Environment and Pollution, 1, 158-168. http://dx.doi.org/10.5539/ep.v1n2p159

Lee, C. L., \& Jou, C. J. G. (2013). Microwave-induced degradation of chlorobenzene using $\mathrm{Fe}^{0}$ and $\mathrm{TiO}_{2}$ coated on cordierites as catalyst. Environment and Pollution, 2, 73-80. http://dx.doi.org/10.5539/ep.v2n1p73

Lee, C. L., Jou, C. J. G., \& Wang, H. P. (2010). Enhance Degradation of Chlorobenzene in Aqueous Solution using microwave-induced zerovalent iron and copper particles. Water Environmental Research, 82, 642-647. http://dx.doi.org/10.2175/106143009X12529484816033

Lee, C. L., Lin, C., \& Jou, C. J. G. (2012). Microwave-induced nano-scale zero-valent iron to degrade perchloroethylene and pentachlorophenol. Journal of the Air \& Waste Management Association, 6, 1443-1448. http://dx.doi.org/10.1080/10962247.2012.719579

Lee, S., Keskar, G., Liu, C. C., Schwartz, W. R., McEnally, C. S., Kim, J. Y., Pfefferle, L. D., \& Haller, G. L. (2012). Deactivation characteristics of $\mathrm{Ni} / \mathrm{CeO}_{2}-\mathrm{Al}_{2} \mathrm{O}_{3}$ catalyst for cyclic regeneration in a portable steam

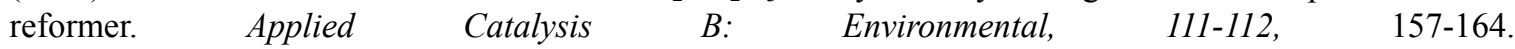
http://dx.doi.org/10.1016/j.apcatb.2011.09.030

Marafi, M., \& Stanislaus, A. (2008). Spent hydroprocessing catalyst management: A review Part II. Advances in metal recovery and safe disposal methods. Resources, Conservation and Recycling, 53, 1-26. 
http://dx.doi.org/10.1016/j.resconrec.2008.08.005

Mazzieri, V. A., Pieck, C. L., Vera, C. R., Yori, J. C., \& Grau, J. M. (2008). Analysis of coke deposition and study of the variables of regeneration and rejuvenation of naphtha reforming trimetallic catalysts. Catalysis Today, 133-135, 870-878. http://dx.doi.org/10.1016/j.cattod.2007.12.118

Nagaoka, K., Seshan, K., Aika, K. I., \& Lercher, J. A. (2001). Carbon deposition during carbon dioxide reforming of methane-comparison between $\mathrm{Pt} / \mathrm{Al}_{2} \mathrm{O}_{3}$ and $\mathrm{Pt} / \mathrm{ZrO}_{2}$. Journal of Catalysis, 197, $34-42$. http://dx.doi.org/10.1006/jcat.2000.3062

Rajaei, H., Amin, A., Golchehre, A., \& Esmaeilzadeh, F. (2012). Investigation on the effect of different supercritical fluid extraction process on the activation of the R-134 catalyst. Journal of Supercritical Fluids, 67, 1-6. http://dx.doi.org/10.1016/j.supflu.2012.02.005

Tonna, B., \& Peretz, J. H. (2007). State-level benefits of energy efficiency. Energy Policy, 35, 3665-3674. http://dx.doi.org/10.1016/j.enpol.2007.01.009

Venkatesh, M. S., \& Raghavan, G. S. V. (2004). An overview of microwave processing and dielectric properties of agri-food materials. Biosystems $\quad$ Engineering, $\quad 88, \quad 18$. http://dx.doi.org/10.1016/j.biosystemseng.2004.01.007

Veziroğlu, T. N., \& Şahin, S. (2008). 21st Century’s energy: Hydrogen energy system. Energy Conversion and Management, 49, 1820-1831. http://dx.doi.org/10.1016/j.enconman.2007.08.015

\section{Copyrights}

Copyright for this article is retained by the author(s), with first publication rights granted to the journal.

This is an open-access article distributed under the terms and conditions of the Creative Commons Attribution license (http://creativecommons.org/licenses/by/3.0/). 